\title{
O TRANSEXUALISMO COMO SUPLÊNCIA NA PSICOSE
}

Laure Westphal

CRPMS (Centro de Pesquisa em Psicanálise, Medicina e Sociedade), Universidade Paris 7, Diderot, Paris, França.

Doutora em
Psicanálise e
Psicopatologia
(PhD),
pesquisadora
associada do
CRPMS (Centro
de Pesquisa
em Psicanálise,
Medicina e
Sociedade),
Universidade
Paris 7 Diderot.
Psicóloga clínica
do setor de
psiquiatria/adulto,
Centro Hospitalar
Marc Jacquet em
Melun.

Melun.
RESUMO: Pretende-se demonstrar que o sujeito psicótico, persuadido a se transformar em mulher, pode fazer do transexualismo uma suplência, na medida em que pode resolver sua dissociação corporal e psíquica ao fazer-se existir enquanto mulher no campo social. Nosso método consiste em comparar a saída do empuxo-à-mulher no delírio de metamorfose paranoica com o arranjo que ele faz no transexualismo. Nossos resultados mostram que essas duas clínicas distintas estão fundadas em uma base comum, que é a de regular o excesso de gozo não regulado pela função fálica. A discussão mostra que o transexualismo se distingue do delírio, fazendo da exceção feminina aquilo que articula as dimensões imaginária e simbólica. Como conclusão, o transexualismo regula o empuxo-à-mulher e permite ao sujeito a constituição de uma nova identidade que une o gozo do corpo e dá a ele um nome.

Palavras-chave: Psicose, transexualismo, empuxo-à-mulher, suplência.

ABSTRACT: Transsexualism as a suppleance in psychosis. The purpose of this article is to demonstrate that the psychotic subject who is confident to be a woman, can turn transsexualism into a means of supplementing that can reduce physical and psychological dissociation while existing as a woman in the social field. Our method is to compare the outcome of the "push-to-woman" delirious paranoid metamorphosis with the development of which it is the object in transsexualism. Our results show that these two distinct clinical situations are based on common issues, such as regulating the excess of unbounded enjoyment by the phallic function. The discussion shows that transsexualism is distinct from delusion by making the female exception the issue that articulates the imaginary and symbolic dimensions. In conclusion, transsexualism regulates the "push-to-woman" process and allows the subject to build a new identity that encompasses enjoyment of the body and gives it a name.

Keywords: Psychosis, transsexualism, push-to-woman, suppleance. 


\section{INTRODUÇÃO}

A psiquiatria tem observado a tendência à feminização vivida por certos pacientes psicóticos. Richard Von Krafft-Ebing (1895) falou deste fenômeno em termos de inversão sexual, cuja expressão varia de "hermafroditismo psicossexual” a "metamorfose sexual paranoica”. É como se a dissociação corporal e psíquica levasse o sujeito, em alguns casos, a tornar-se mulher. Mas existem também situações em que a convicção de um homem de ser mulher não vem acompanhada de nenhum fenômeno elementar. Nomeou-se "transexualismo” esta entidade clínica. Alguns psicanalistas veem aí o indício de uma psicose compensada. Podemos citar, dentre eles, Marcel Czermak (1996). Outros, como Jean-Claude Maleval (1998), preferem falar de formação imaginária e, por isso, não a relaciona com uma estrutura precisa. O essencial para a psicose hoje é saber se o homem convencido a ser mulher pode enfim esperar uma reconciliação corporal e psíquica, demandando para a medicina um corpo feminino. Tentaremos compreender essas questões buscando no cerne da clínica das psicoses o que aproxima a metamorfose corporal e a convicção de ser mulher, como, por exemplo, a rejeição da função fálica ou a relação à exceção feminina, mas também o que os separa, na medida em que o transexualismo tem por particularidade ser legitimado pelo discurso social.

\section{O TRANSEXUALISMO: EVOLUÇÃO E DEFINIÇÃO}

O transexualismo é identificado como uma entidade clínica isolada no meio do século XX e goza, desde então, de um interesse constante. Em 1966, Harry Benjamin o distingue do travestismo e o define como sendo o sentimento de pertencer a outro sexo. Robert Stoller (1968) diz também que o transexualismo repousa menos sobre a vontade de parecer com o outro sexo que sobre a convicção de fazer parte dele, insistindo sobre a permanência desta convicção inabalável. Jean-Marc Alby (1956) acrescenta que os transexuais vivem a morfologia como um “erro da natureza”. Esta expressão parece bem-vinda, já que eles a utilizam sobretudo para explicar a vivência de prejuízo: os órgãos sexuais primários e secundários são deformidades repugnantes e devem ser corrigidos. A medicina propõe uma reviravolta quando começa a agir apoiando-se no progresso científico. As coisas mudam também para os pacientes, não mais condenados a se automutilarem, mas podendo solicitar ao endocrinologista uma modificação dos caracteres sexuais secundários e a realização de uma cirurgia de mudança de sexo.

Esta evolução recoloca em questão a terminologia a ser empregada. Se se fala de "mudança de sexo", subentende-se que ela é ligada ao arbitrário da vontade. Se se fala de "resignação ao sexo", reconhece-se o "erro da natureza” e o prejuízo psíquico. Pode-se também discutir as expressões transexualismo mas- 
culino, quando um homem se diz mulher, e transexualismo feminino, quando uma mulher se diz homem. Tal como Jacques Breton em 1985, os transexuais contestam esta escolha semântica e acham mais justo falar em transexualismo feminino para uma "mulher presa no corpo de um homem", e reciprocamente. O que é recolocado em questão com a semântica clássica é o privilégio concedido à anatomia, ao passo que há uma tendência a favorecer a realidade psíquica. Isso é certo, ao menos, em todos os países que entraram em acordo sobre os Standards of Care da HBIGDA (SOC), autorizando os transexuais que fazem o pedido para a realização da operação de conversão, com a condição de que eles tenham atravessado as seguintes etapas: um diagnóstico psiquiátrico, algumas sessões de psicoterapia e uma experiência de vida no outro sexo.

Agora que a medicina e o discurso social admitem a vivência feminina por um homem, o sujeito psicótico não poderia ser capaz de fazer sua inscrição do lado feminino na relação com o Outro? Sublinhamos que a articulação de uma identidade no campo do Outro ou no campo social é a definição às vezes dada à suplência. Mais precisamente, o psicótico convencido de ser mulher poderia diminuir a dissociação corporal e psíquica, tornando-se psiquicamente e socialmente mulher? Esta hipótese, fio condutor de nosso artigo, sugere que focalizaremos a questão na situação do homem que se diz mulher, sem pretender tirar conclusões sobre a situação inversa, na qual o que está em jogo é diferente.

\section{A DISTINÇÃO ENTRE O DELÍRIO DE METAMORFOSE CORPORAL E 0 TRANSEXUALISMO}

Em relação à clínica do corpo, qual a diferença existente entre um delírio de metamorfose feminina e a convicção de ser mulher?

Em Memórias de um doente de nervos, Daniel Paul Schreber (1903) descreve a maneira como um corpo se deforma, se desintegra e volta a ganhar consistência graças à hipocondria. Esta solução funciona até que ele é eleito Presidente do Reichtag e interpelado no lugar do significante forcluído. Em seguida, a hipocondria não é mais suficiente para conter a sensação de metamorfose originária, deixando-o perplexo diante da transformação de suas partes genitais, "emasculação milagrosa" de seus pelos da barba e, finalmente, diante da "transformação de toda a ossatura $[\ldots]$ consistindo $[\ldots]$ em um amontoado de vértebras $[\ldots]$ e também da substância óssea das coxas" (p.180). O excesso de gozo que conseguia se localizar em algumas partes do corpo domina agora todo o corpo e isso produz sentido: "a volúpia da alma tinha se tornado tão forte que passei a aceitar a configuração de um corpo feminino - inicialmente em meus braços e mãos e, mais tarde nas pernas, nos seios, nas nádegas e em todas as partes do meu corpo" (p.207). 
Horrorizado, ele se sente face à "alternativa de enlouquecer-se, conservando seus atributos masculinos ou tornar-se mulher, mas sã de espírito” (p.209).

O transexualismo, tal qual se exprime em outros pacientes hoje, mostra que existe uma convicção inicial de ser mulher. No primeiro momento, os transexuais temem a loucura, e a formulam frequentemente assim: "em um corpo de homem, não sou eu”, "meu corpo não é o que eu sou” ou ainda "eu sou uma mulher presa em um corpo de homem". Estas expressões atestam a inadequação da realidade anatômica à realidade subjetiva, e não o contrário. É então o corpo que deve se transformar para corrigir a experiência de estranheza. Mas é difícil unir o corpo ao significante. Primeiro, “a mulher nascida no corpo de um homem" diz se comportar "como" um homem, e quando ela tenta "se realizar", os outros dizem que ela se comporta “como” uma mulher. Uma transexual tailandesa, chamada de Katoey em seu país, disse: "eu tentei ser homem, mas era uma tortura... para satisfazer os outros. Para que me infligir isso?". Ao contrário de D.-P. Schreber, os transexuais evocam uma disforia entre o gênero original que legitima todos os esforços para obter as transformações corporais. O travestimento não é suficiente, a roupa deve vestir um corpo de mulher.

\section{A DIALÉTICA DO PÊNIS E DO FALO}

Quando um homem descreve a feminização de seu corpo, ele altera a ideia tão evidente que temos às vezes que pertencer psiquicamente ao 'nosso' sexo anatômico. Entretanto, S. Freud (1905) já sublinhava que a diferença anatômica valia por suas consequências psíquicas, subtendendo que elas não valem por si mesmas. J. Lacan (1961-62) interessou-se por essa questão e também, ao mesmo tempo, pela função do falo na identificação do sujeito. Segundo ele, no estágio fálico “o pênis não é mais fálico quanto o seio não é mamário” (p.134). Ele substitui o seio. Mas mesmo se o pênis é relegado à mesma categoria que o conjunto de objetos atingidos por ele nesse estágio, o sujeito se faz fálico, pois a função significante do falo coloca o pênis diante de uma ameaça: a ameaça de castração que determina a angústia correspondente. O pênis é elevado então à categoria de falo.

Em seu seminário Ou pior (1971-72), J. Lacan dialetiza a função significante do falo com o processo de sexuação, que é decomposto em três tempos lógicos. O primeiro é o tempo da diferença natural dos sexos, que é um real mítico. Com efeito, ele só adquire valor em um segundo tempo, o do discurso sexual, que interpreta os dados sob o peso do famoso significante único, o falo, categorizando a diferença sexual em termos de castração. Por fim, o terceiro tempo é o da escolha do sexo pelo sujeito, ou, dito de outra forma, o da "opção de identificação sexuada”. 
J. Lacan escolhe a expressão "erro comum" para qualificar o processo universal que consiste em fazer passar o falo do estatuto de significado do gozo para o de significante mestre do discurso sobre o sexo. Se o sujeito não comete este erro, ele é vítima de um outro, seu inverso: o "erro da natureza", de que se queixa justamente o homem que se sente mulher. O testemunho de D.-P. Schreber está aí para nos mostrar que recusar a significação fálica não exclui o fato de ser habitado pelo significado fálico, protestando virilmente. É assim que através de algumas remediações seu corpo e sua subjetividade se feminizam, afrouxados pelas identificações masculinas efetivas até então. Para o transexual, a forclusão do falo se exprime de outra forma: ele recusa de cara e sem contradição que o órgão seja interpretado de forma fálica.

\section{A SUPRESSÃO DA FORÇA DO EXCESSO PULSIONAL}

O que sucede com o pênis nessas circunstâncias em que o sujeito recusa a significação fálica? Sendo preservado de qualquer ameaça, o pênis continua a ser uma parte do corpo real. Ele não é falicizado. É então o sujeito que está destinado a ser o falo, encurralado no gozo do Outro. No lugar de ser ameaçado, o órgão torna-se ameaçador, pois o discurso não interpreta a pulsionalidade. Ela permanece insensata e frequentemente tem como efeito invadir todo o corpo, despedaçando-o. O órgão peniano persegue tanto quanto o conjunto do corpo. Uma apresentação clínica realizada por J. Lacan a respeito de Michel H. (um paciente hospitalizado por tentar se enforcar) em 1976 (CZERMAK, 1996) exemplifica esta situação. O paciente exprime para J. Lacan seu antigo gosto de se revestir com roupas de menina e a "pena" que provém do fato de ser homem. Conta que seis meses antes da entrevista os medicamentos deram-lhe a impressão de "reencontrar seu personagem". A angústia foi tal que, diz ele, "eu tentei me castrar". Não o conseguiu em função de uma dor muito aguda.

Quando o sujeito é objetalizado pelo gozo do Outro, pode querer cortá-lo, criando a falta no real. Esta lógica leva à passagem ao ato suicida ou, ainda, à automutilação, como mostra o exemplo narrado acima. Com efeito, o sujeito não quer que o assimilemos ao falo por ele deter o pênis, e está pronto a emascular-se para evitar esse erro. Suprimir a força pulsional dá-lhe também a esperança de bloquear o excedente de gozo materno. De alguma maneira, a operação de castração é destinada a neutralizar a tomada ao pé da letra desta proposição: "as mulheres querem o pênis".

Michel H. foi bastante documentado. Ele aprendeu notadamente "que se pode se castrar, ter seios com hormônios, chegar a verdadeiramente se metamorfosear um homem em mulher". Decidido a tornar-se mulher, sem esquecer seu personagem e não ficar mais angustiado por ser homem, ele já definiu com os 
cirurgiões e esteticistas que quer modificar o resto do corpo. Alguns afirmam que o transexual rejeita o órgão no lugar do significante, mas será que não é esta sua maneira de resolver o problema do gozo sexual, muito real em função da disjunção do falo? Colocar-se sob o significante 'mulher' o permitiria também agenciar de outra forma toda a problemática corporal.

\section{DIFERENTES RELAÇÕES COM O GOZO}

O psicótico ligado ao significante 'mulher’ não cultiva uma ambiguidade? Quando se aceita a função fálica, pode-se inscrever nela de duas formas. A escolha masculina e a escolha feminina correspondem às duas "opções de identificação sexuada" e às relações distintas ao gozo na referência ao falo. J. Lacan descreve o que está em jogo nessas duas posições no seminário Mais, ainda (1972-73) e no Aturdido (1973).

J. Lacan explica a inscrição do lado 'homem', dialetizando a aproximação freudiana do complexo paterno com a lógica aristotélica do universal e do "todo", fundada sobre o princípio da contradição. Para ele, existe uma contradição formal entre a existência necessária de um ponto de exceção à função fálica, o pai, de um lado; e, de outro, a regra universal fálica que faz o homem. De alguma maneira, ele reescreve em termos lógicos o mito Totem e tabu (FREUD, 1913), segundo o qual o pai da horda é este ao menos um que não é submetido à lei da castração: ele goza de todas as mulheres, ainda que morto. O sujeito se inscreve do lado 'homem' se ele aceita, no princípio da castração, a exceção paterna à lei fálica. A exceção faz a regra.

Para J. Lacan, a sexuação feminina aceita também esta exceção à regra, mas ela é caracterizada por uma lógica especial de negação colocada no todo. O sujeito tem como referência o falo, sem que esta referência seja a única, e sem que outro significante mestre sirva de referência. Esta lógica inédita do "não-todo" é correlativa a uma relação inédita com o gozo. O gozo feminino é "não-todo" fálico, isto é, em parte inscrito na função fálica e em parte "louco", isto é, não regulado pelo Édipo.

E na psicose? A lógica da sexuação sugere que, para se inscrever tanto do lado masculino como do lado feminino, é preciso a referência a um conjunto de elementos submetidos à função fálica e aceitar que exista uma exceção. Em cada caso, o sujeito admite que existe ao menos um que não é submetido à função fálica. O problema é que é o lugar do Pai, que é justamente não localizado na psicose. O psicótico se inscreve então do lado feminino, não se beneficiando de uma exceção que o tire da lógica do "tudo ou nada”. Como sublinha Augustin Ménard (2011). O resultado disso é um “empuxo-à-mulher”, mostrando um gozo que, por sua parte, não é, de maneira alguma, fálico. 


\section{A CLÍNICA DO "EMPUXO-AO-ATO": SEU INVERSO}

Se o significante do Nome-do-Pai está forcluído, a indivisão do sujeito o leva para o lado feminino, ao ponto de encarnar literalmente 'A mulher no real'. O tornar-se mulher é a ilustração maior dos efeitos da forclusão na psicose. Vê-se isso também no delírio paranoico de transformação em mulher e na convicção de ser mulher. Terrificado pela transformação em mulher, D.-P. Schreber adia o fracasso para mais tarde, graças ao trabalho do delírio. Com efeito, o universo queria fazê-lo afrontar a eviração, mas ele "exclui" um tal acontecimento. O problema é que esta sórdida feminização insiste. Assim o suplício de eviração se reaproxima e ele tem o mesmo objetivo: gozar como uma mulher sob o efeito da penetração sexual realizada pelos homens. O tornar-se mulher é sinônimo de degradação somente para D.-P. Schreber em função de suas identificações masculinas?

Uma entrevista conduzida por M. Czermak com Nicolas P. (1996) mostra a que ponto "ser mulher", para o transexual, não é negociável. Assim que M. Czermak se endereça a ele pelo seu nome, Nicolas P. retruca: "Não, Carole. Eu sou a Carole". Nicolas P. se explica dizendo que desde pequeno brincava com as meninas. E acrescenta: "brincar com os meninos me provocava horror, eu tinha vergonha quando eu tomava banho com os meninos, se eles me acariciavam e me abraçavam, me dava medo”. Quando ele era “completamente menino”, era desejado pelos outros e se sentia humilhado. Ele os evitava, pois não queria também ser associado a isso. Nicolas P. sempre considerou que pertencia ao sexo feminino. E hoje não quer ser humilhado como foi quando se tornou homossexual: "A homossexualidade é qualquer coisa de vicioso, não é natural. Eu estimo que o homossexual fiel deva se decidir em tornar-se mulher completamente ou permanecer homem”. Esta vergonha tão tenaz o impedia, em determinados momentos, de sair na rua. Mas está melhor: decidido a ser amado como uma mulher por um homem.

Tanto para D.-P. Schreber quanto para Nicolas P., ser um homem feminizado é expor-se à degradação sexual. É assim que J. Lacan qualifica o empuxo-à-mulher de "sardônico". Seu caráter mortificante vem do excesso de gozo associado ao significante 'mulher', segundo um agenciamento capaz de levar ao fracasso. Existiria assim um seguimento lógico entre a rejeição da função fálica, a rejeição do pênis para dominar seus efeitos e a pressão à identificação ao objeto a, caso o "ser mulher" não seja algo sublimado.

\section{A ELEIÇÃO DO SIGNIFICANTE 'MULHER'}

Visto de perto, ser mulher não é projeto sedutor? É o que D.-P. Schreber oprime na medida em que seu delírio progride, e é do que os transexuais estão conven- 
cidos no início de seu percurso. Esta satisfação passa pela pacificação da ligação entre o sentimento de pertencimento ao sexo feminino e a escolha de objeto ou está em outro lugar?

Retomemos o exemplo de Michel $\mathrm{H}$. Ele não associa o objeto específico ao seu gozo. Aos 22 anos, experimentou relações tanto com homens quanto com mulheres, "para ver quem era a pessoa que melhor (o) convinha". No final das contas, não havia nenhum: "nem um nem outro me atraem". Suas duas primeiras relações sexuais foram com uma mulher e deram-lhe o prazer da penetração, mas ele disse: "havia alguma coisa de mais forte em mim que me contradizia". A terceira e última relação com uma mulher foi vivenciada como um concubinato, "como dois homossexuais". Com ela, diz, "eu estava sempre vestido de mulher, mesmo na penetração, e eu me sentia mulher na relação sexual”. Michel H. amava ser amado como mulher. Em compensação, sentiu-se frequentemente "abusado" ou ridicularizado pelos homens quando saía como travesti. Ainda antes de ser hospitalizado, tentou manter relações sexuais com dois amigos de infância, mas sem conseguir ir mais longe nas carícias. Ele não pode se sentir mulher nos braços de um homem. Michel $\mathrm{H}$. se interessa pela sexualidade com a condição de se abrir como mulher e com uma mulher. Esta identificação com a mulher é que é gozosa. Inclusive, necessária: "eu prefiro sacrificar minha vida, não ter filhos, não ter nada, mas ser uma mulher".

Nicolas P. escuta ainda mais seu desejo sexual que 'confirma' seu pertencimento ao sexo feminino: "eu não tenho necessidade de uma mulher, eu tenho necessidade de homem. A sodomização não me satisfaz e me incomoda". Ele adora acariciar o homem como uma mulher, e tem necessidade de ser amado como uma mulher: "o transexual reage na mesma zona erógena da mulher, nossa pele é muito sensível, temos orgasmo quando nos fazem carícias, beijos. Como uma mulher, esperamos a virilidade do homem". Seu voto mais caro é o de deixar exprimir a mulher que cresce nele: "meu psiquismo, meus pensamentos são de mulher, mas meu corpo não é ainda completamente feminino [...] Eu me vejo como uma mulher, eu tenho pensamentos femininos, eu me deleito diante das bijuterias, de belos casacos de pele, diante de belos homens, eu me deleito quando cozinho, quando faço compras, quando se dirigem a mim no feminino...". Deixa claro que a beleza das mulheres não o excita. É o seu projeto que o seduz: "ser bela, uma mulher graciosa, uma mulher que pode interessar aos homens".

Para Michel H., o "desejo" de ser mulher não é suficiente, enquanto para Nicolas P. o amor de um homem deve se conjugar a isso. Isso nos faz pensar em Freud, para quem a feminilidade schreberiana se explica a partir de uma negação da homossexualidade. Esta também é uma das hipóteses de M. Czermak em relação a Nicolas P. Entretanto, perguntamo-nos se não se trata menos de uma homossexualidade recalcada do que de uma homossexualidade emprestada, 
destinada a justificar a inscrição do lado feminino. Na psicose, qualificar o gozo de feminino seria uma maneira de interpretá-lo, através da sexuação. Inclusive, escolher o significante 'mulher' permite a busca existencial de fazer do transexualismo a saída para o empuxo-à-mulher.

\section{O EMPUXO Ȧ EXCEÇÃO}

Se nomear o gozo o legitima, ele não é por essa razão circunscrito, já que falta um ponto de exceção para regular a pulsão. Com efeito, quando o sujeito psicótico recusa a exceção que justifica o conjunto de homens, ele não está em posição de se considerar como único em relação a este conjunto. Ele tem mais o sentimento de ser um elemento particular de um todo sem exterioridade, o que o expõe às angústias de despedaçamento. Ora, frequentemente, não lhe falta a intuição de que se trata de criar ou inventar esta exceção. É assim que, para A. Ménard (2011), o sujeito psicótico pode pretender ser "como Schreber, a mulher que falta aos homens - mas também o chefe que falta ao povo, o patriarca que falta à família, o artista que falta à nossa época" (p.138). Se a busca de um destino excepcional torna o gozo suportável, ela também consegue constituir um sinthoma. Como o tornar-se mulher é estruturalmente posto na psicose, não é incongruente buscar a exceção no campo da feminilidade.

J. Lacan (1958) confirma que a exceção possui uma ligação privilegiada com a feminização, na medida em que esta última é sustentada pelo Ideal do eu. Assim, ela interroga a dimensão simbólica. Por exemplo, a paranoia de D.-P. Schreber mostra que assumir-se fora-da-lei cria, ao mesmo tempo, uma nova ordem do mundo ao redor do ser feminizado. No transexualismo, sem outros elementos delirantes, é "A mulher" que é o nome do ponto de exceção à lei e o sustento de uma nova ordem do gozo. A psicose queria que o ser "fora-da-lei" e o significante "mulher" evoluíssem de maneira assintótica, com uma convergência para um ponto único. Para A. Ménard (2011), o qualificativo de "assintótico", tomado emprestado de S. Freud por J. Lacan, deve ser lido no "empuxo-à" do empuxo-à-mulher.

Assim, o avesso mortificante do empuxo-à-mulher teria como metáfora delirante um lugar. O lugar do transexualismo é a idealização d'“A mulher" como horizonte infinito. Uma nota deve ser acrescida para dizer que o estatuto do Outro se modifica no mesmo movimento: ele era desvalorizado enquanto que se espera dele que legitime o sujeito que constrói sua nova identidade. Isso se produz, por exemplo, quando o transexual se forja um modo de ser no mundo valorizado pela sociedade: quando um sistema promete este modo de feminização ou quando um microcosmo social é fundado sobre esses valores. Caso contrário, o novo estatuto do empuxo-à-mulher se insere nos laços sociais 
e este estatuto constitui uma suplência. “A mulher” é capaz não somente de inverter o sentido dado ao gozo, mas também de consolidar sua dialetização com a exceção feminina.

\section{A EXCEÇÃO "FEMININA"}

O transexualismo masculino se distingue de seu homólogo feminino pela importância conferida à beleza. A mulher "nascida em um corpo de homem” busca frequentemente se distinguir no campo estético, dando a impressão, para aquele que a olha, de ser uma caricatura feminina "mascarada”. D.-P. Schreber teve que reconhecer que sua força de atração sobre os raios modificou seu pertencimento e a importância que conferia a eles: "Desde então, é em plena consciência que eu inscrevi, sobre os estandartes, o culto da feminilidade e, de agora em diante, eu me sustentarei nele tanto quanto me permitirão os olhares ao meu redor".

Por seu lado, os transexuais buscam ativamente a estética feminina. Eles optam em geral por um travestimento privado, depois público, cultivando o perfeccionismo. O corpo não é nunca um resto, já que é modificado paralelamente. O corpo é a princípio modificado pela plástica, por meio do cabelo ou dos pelos, por exemplo, antes que os caracteres sexuais secundários sejam “corrigidos”. Entre estes: a pele, os seios, a voz. É Michel H. quem fala melhor sobre esta forma de organização visível do sintoma, para parafrasear M. Foucault.

No hospital, Michel H. fracassa "em segurar a onda”, pois lhe faltam as roupas de mulher. Ele fica nervoso, mas quando está vestido de mulher, todo o seu corpo experimenta um alívio, uma satisfação. Michel H. quer se tornar uma bela mulher, eventualidade propagada pela mídia científica: "um homem poderia ser muito mais esguio, mais bonito, muito mais doce que uma verdadeira mulher". Esperando isso, Michel H. forjou para si um personagem feminino, Corinne, por quem nutre verdadeira adoração quando esquece que é homem. Vários transexuais dividem este discurso com Michel $\mathrm{H}$.

Na Tailândia, as katoeys são conhecidas por quererem ter também um estatuto de exceção e sobressair-se no campo da beleza feminina. Inclusive, obtêm um estatuto particular desde a escola primária, onde são dedicados a elas locais próprios. Mesmo nas clínicas onde elas operam, onde são cultivadas e, por fim, na mídia, na qual sua notoriedade é cultivada. Existe no país um concurso de beleza muito mediatizado consagrado às katoeys. Este evento as honorifica, e elas o apreciam. Uma delas diz: “é legal mostrar que nós, katoeys, podemos ser mais belas que as mulheres". Um admirador do concurso de "miss" veio de longe para este evento e comentou: "com sua graça e talento, elas provocariam complexos nas mulheres". 


\section{A IDENTIFICAÇÃO "SECUNDÁRIA" COMO AUTOENGENDRAMENTO}

Qual é o alcance da apresentação feminina nos dois casos? D.-P. Schreber tinha um temor de ter sido "feito a seis quatro dois", uma forma elegante que seu delírio lhe deu. Os transexuais sofreram bastante com os erros cometidos pela natureza para gozar da apropriação reparadora dos indícios de feminilidade. Mas os transexuais querem que essa reparação aconteça também no real: "queremos operar para sermos normais", ou ainda “a mudança de sexo não é uma cirurgia plástica, é uma cura”, dizem. Na verdade, desejam que o corpo se fixe no significante "mulher", o qual acreditam que os define melhor.

É interessante escutar o que os transexuais têm a dizer depois da operação. Vejamos o que afirma um deles: “depois que eu mudei de sexo, minha vida está melhor e não me sinto um deficiente, o Dr. X que me operou é um segundo pai para mim, ele me transformou em alguém completo, acabado”. Pedir para retirar o pênis não é então um capricho, é inventar um pai castrador que permite ao corpo tomar forma em torno do furo deixado pela extração. Um outro transexual operado confirma: “é como se meu corpo, que havia em parte sido ignorado até então, ganhasse sentido”. O corpo cuja aparência é, a partir de agora, coerente com a vivência feminina, pode renascer.

Mas operar não é o essencial. O que importa para o transexual é sobretudo forçar a admiração do Outro, para quem a metamorfose se endereça. Seduzir evacua o obsceno e permite recuperar a dignidade. M. Czermak (2001) analisa a reivindicação de dignidade como a busca de uma imagem ideal, uma espécie de Eu ideal, engendrado a partir de fantasmas que ele centraliza. Como se o sujeito atingisse uma identificação a partir da distância a ser reduzida entre uma imagem desvalorizada e uma representação gloriosa. Os transexuais mediatizados são um exemplo disso, existindo como estrelas no campo social. Mas de maneira geral, querer encarnar "a” mulher revela um semblante de identificação secundário, tendo o alcance de uma identificação primordial. Embelezar o corpo mostra menos uma mascarada fálica do que escópica, permitindo ao sujeito inscrever-se na relação com o Outro. Isto justifica a proposição de M. Safouan (1974): “o transexual não brinca de mulher, ele é uma mulher".

\section{A NOMINAÇÃO}

Ser uma bela mulher está destinado a ser um suporte identificatório, mas demanda ainda um reconhecimento simbólico. Isso é verdadeiro tanto para D.-P. Schreber, que busca dar sentido para a sua metamorfose, quanto para os transexuais, que reatualizam o ato de nominação.

No caso de D.-P. Schreber, consentir em ser a mulher de Deus não está articulado a um projeto qualquer: "eu acredito não me enganar quando eu digo que 
finalmente uma parte especial da vitória está reservada para mim”. A honra viril que lhe é retirada será devolvida de outra forma e, de acordo com ele, o alcance dessa indenização está longe de ser estéril:

“a eviração, que teria como consequência, depois da fecundação divina, uma nova linhagem; ou ainda com esta outra consequência que meu nome seria, de agora em diante, ligado a um renome tal jamais ele fracassaria em divisão com nenhum dos milhares de homens de espírito incomparavelmente superiores que viveriam antes de mim." (SCHREBER, 1975, p.331)

A forclusão do Nome-do-Pai e do falo dá lugar a uma feminização cujo destino é recuperado dignamente: D-P. Schreber parirá como uma mãe e dará seu nome como um pai.

O transexualismo demanda o simbólico de outra forma. De acordo com S. Ginestet-Delbreil (2003), esta clínica interpela a coocorrência de noções de identificações e de autoengendramento. Para compreender isso, a autora se refere ao estágio do espelho, em que J. Lacan (1966) fez o momento da emergência do sujeito na assunção jubilatória de sua imagem especular. Este surgimento está relacionado a uma "identificação no sentido pleno que a análise dá a este termo, a saber, a transformação produzida no sujeito quando ele assume uma imagem" (p.94). O surgimento do sujeito confirma isso, quando o nome extrai a criança da prisão ligada à troca de olhares.

Alguns dizem que o transexual investe unicamente no eixo imaginário: ser mulher mostrando a fixação em uma imagem sem que esta seja apoiada em dados significantes. E esquecendo o nome que se dá ao sujeito no curso de sua busca de metamorfose. Ele não pode ter sido dado pelo Outro, mas ele o tomou para si, o que demonstra a aspiração do sujeito ao simbólico para consolidar a identificação com a imagem. No transexualismo, a nominação é tão central quanto a dignidade, pois a mudança de estado civil supõe retirar dos documentos de identidade o nome de origem para substituí-lo por outro, introduzido pelo tão esperado significante 'Senhora'. Para M. Czermak (1996), “esta mulher que o transexual quer ser e que atribui a este ser dotado de beleza, de completude, esta genitora universal, este todo em um, esta mulher se apresenta como A mulher, ou seja, um dos Nomes-do-Pai".

\section{CONCLUSÃO}

Na psicose, a forclusão do Nome-do-Pai impede o acesso ao gozo fálico do corpo, que insiste. Ele se apresenta sob a forma do empuxo-à-mulher, por exemplo, no delírio de metamorfose paranoica, mas também no transexualismo. Esta 
comparação nos permite compreender que situações comuns podem ter destinos diferentes. De um lado, o transexualismo se singulariza, permitindo o agenciamento do corpo ao significante 'mulher' logo que o sujeito se inscreve em uma ideia de realização. Tornar-se a exceção feminina, ser renomeada, é o ponto de captação desta mudança. Não é um sintoma que integra a função do desejo do Outro? Reencontrar a dignidade em um corpo feminino demanda, com efeito, o assentimento do Outro. Quando o transexual solicita aos médicos modificações corporais e uma mudança de estado civil, ele o faz de sorte que se agenciam duas dimensões complementares: de um lado, solicita à medicina, cuja vocação é restabelecer a saúde do corpo; de outro, solicita ao direito, cujo papel é harmonizar as relações sociais. O transexualismo, para o sujeito psicótico, serve para harmonizar o corpo ao significante 'mulher' destinado a representar ou reabsorver a dissociação corporal e psíquica na relação com o Outro e no campo social.

Recebido em 19/1/2015. Aprovado em 20/2/2015.

\section{REFERÊNCIAS}

ALBY, J.-M (1956) Contribution à l'étude du transsexualisme, Thèse de médecine (juin, n.665), Paris.

BONIERBALE, M., MICHEL A., LANÇON C. (2005) “Le corps transformé", l'Information Psychiatrique, 81(6), p.517-28.

BENJAMIN, H. (1966) The transsexual phenomenon. New York: The Julian Press, Inc. publishers.

BRETON, J., FROHWIRTH, C., POTTIEZ, S., KINDINIYS, S. (1985) Le transsexualisme: étude nosographique et médico-légale. Paris: Masson.

BUTLER, J. (2005) Trouble dans le genre. Le féminisme et la subversion de l'identité. Paris: La découverte.

CASTEL, P.-H. (2003) La métamorphose impensable, essais sur le transsexualisme et l'identité personnelle. Paris : Gallimard.

CHILAND C. (2011) Changer de sexe, illusion et réalité. Paris: Odile Jacob.

COLEMAN, E., BOCKTING, W., BOTZER, M., and al. (2011) Standards of Care for the Health of gender, and gender-nonconforming people, Version 7, International Journal of Transgenderism, n.13, p.165-232.

CZERMAK, M. (1996) Sur l'identité sexuelle. A propos du transsexualisme. Paris: L'association Freudienne Internationale.

. (2001) Passions de l'objet. Etudes psychanalytiques des psychoses. Association Freudienne.

DOLTO, F. (1984) L'image inconsciente du corps. Paris: Le Seuil. 
ESPINEIRA, K. (2008) La transidentité. De l'espace médiatique à l'espace public. Paris: L'Harmattan.

FOERSTER, M. (2012) Elle ou lui ? Une histoire des transsexuels en France. Paris: La Musardine.

FREUD, S. (1905/1987) Trois essais sur la théorie sexuelle. Paris: Gallimard. (1913/2001) Totem et tabou. Paris: Payot et Rivages.

GINESTET-DELBREIL, S. (2003) Du désaveu à l'errance. Un préalable à la perversion et à d'autres phénomènes. La Riche: Diabase.

HUBERT, H., (2007) Transsexualisme: du syndrome au sinthome, Cliniques méditerranéennes, 2(76), p.255-270.

LACAN, J. (1966) "Le stade du miroir comme formateur de la fonction du je”, Les Ecrits. Paris: Le Seuil. (1955-56) Le séminaire, Livre III, Les psychoses. Paris: Le Seuil. . (1961-62) Le séminaire, Livre IX, L’identification. Paris: Le Seuil. (1971-72) Le séminaire, Livre XIX bis, Ou pire. Paris: Le Seuil. (1972-73) Le séminaire, Livre XX, Encore. Paris: Le Seuil. (1975-76) Le séminaire, Livre XXIII, Le sinthome. Paris: Le Seuil.

MALEVAL, J.-C. (1998) “Le syndrome transsexuel”, Spicilège, les destins sexués du sujet, Département de Psychanalyse, Université Paris VIII, Section clinique de Rennes, Association Mathéma-Rennes.

MÉNARD, A. (2011) Le pousse-à-la femme dans la psychose, Les Cahiers Cliniques de Nice, 6, p.133-140.

MILLOT, C. (1983) Horsexe, essai sur le transsexualisme. Paris: Point Hors Ligne.

MOREL, G. (2000) Ambiguités sexuelles. Sexuation et psychose. Paris: Anthropos/ Economica.

SAFOUAN, M. (1974) Etudes sur l'Eedipe: introduction à une théorie du sujet. Paris: Le Seuil.

SCHREBER, D. P. (1903/1975) Mémoires d'un névropathe. Paris: Le Seuil.

SERRANO, J. (2007) Whipping girl: a transsexual woman on sexism and the scapegoating of femininity. Seal Press.

STOLLER, R. J. (1968) Sex and gender. London: Karnac.

VON KRAFFT-EBING, R. (1895) Études médico-légales: psychopathia sexualis. Avec recherche spéciale sur l'inversion sexuelle, Traduit sur la 8e édition allemande par Émile Laurent et Sigismond Csapo. Paris: Georges Carré.

\section{Referências de audiovisual}

Enquête exclusive (20/05/2012) «Les katoeys: le troisième sexe », M6.

Emission Pink Tele (01/11/2009), «Transgeneration », Daily Motion.

Laure Westphal

laure_westphal@hotmail.fr 